\title{
Unconventional organization of the division and cell wall gene cluster of Streptococcus pneumoniae
}

\author{
Orietta Massidda, ${ }^{1}$ Daniela Anderluzzi, ${ }^{1}$ Laurence Friedli ${ }^{2} \dagger$ \\ and Georg Feger ${ }^{2} \dagger$
}

1 Department of Microbiology, Medicine Research Center, GlaxoWellcome, 37100 Verona, Italy

2 Geneva Biomedical Research Institute, GlaxoWellcome, 14 Chemin des Aulx, $\mathrm{CH}-1228$ Plans-les-Ouates, Geneva, Switzerland

\author{
Author for correspondence: Orietta Massidda. Tel: +39459218548. Fax: +39459218196. \\ e-mail : om96900@glaxowellcome.co.uk
}

\begin{abstract}
The genes responsible for cell wall biosynthesis and cell division (dcw genes) were identified and sequenced in Streptococcus pneumoniae. The genetic organization of the dcw cluster in Streptococcus pneumoniae differed significantly from the clusters of other bacteria reported to date. In particular, the genes corresponding to the $\mathbf{2}$ min region of the Escherichia coli chromosome were found distributed in three genetically separate regions of the Streptococcus pneumoniae chromosome. The first region contained the expected ftsA and ftsZ cell division genes at one end and pbp2b, ddl and murF at the other end. The murD, murG and divIB genes, always found located upstream of ftsA, were found in a second region separated from the first. A third region contained the yIIC, yIID, pbp2x and mraY genes. The chromosomal region downstream of $f t s Z$ was also sequenced and characterized. In Streptococcus pneumoniae this region contains four ORFs, all of unknown function, and an ORF encoding the Bacillus subtilis DivIVA homologue. The gene order and the organization of this region was found to be conserved in Staphylococcus aureus, Streptococcus pyogenes and Bacillus subtilis, raising the possibility that previously unidentified loci may also be involved in division.
\end{abstract}

Keywords: $d c w$ gene cluster, Streptococcus pneumoniae, Staphylococcus aureus, cell division, Gram-positive bacteria

\section{INTRODUCTION}

Many different bacteria, including Gram-negative and Gram-positive rods or cocci, possess a chromosomal region similar to that found at the 2 min region of the Escherichia coli chromosome (Yura et al., 1992; Ayala et al., 1994). This region contains many genes whose products are involved in division and cell wall biosynthesis and is therefore known as the $d c w$ (division and cell wall) cluster (Ayala et al., 1994; Vicente \& Errington, 1996).

Initial comparison between Escherichia coli and Bacillus subtilis $d c w$ clusters showed a remarkable degree of conservation (Henriques et al., 1992; Buchanan et al.,

†Present address: Serono Pharmaceutical Research Institute SA, 14 Chemin des Aulx, CH-1228 Plans-les-Ouates, Geneva, Switzerland.

The GenBank accession numbers for the sequences reported in this paper are AF068901, AF068902 and AF068903 for Streptococcus pneumoniae and AF068904 for Staphylococcus aureus.
1994), not only at the level of sequence similarity among the translated sequences, but also in the organization of the genes and the polarity of their transcription. Both regions contain a $p b p$ gene $(f t s I / p b p B)$ near the beginning of the cluster and $f t s Q(\operatorname{divl} B), f t s A$ and $f t s Z$, next to each other, at the distal end. In Bacillus subtilis, $p b p B$, encoding PBP2B (Yanouri et al., 1993), is duplicated and its homologue, spoVD, has been shown to be expressed differentially during sporulation (Daniel et al., 1994). Three additional members of the cluster, $y$ llB, $y l l C$ and $y l l D$, located upstream of $p b p B$, have been reported in Bacillus subtilis (Daniel et al., 1996). Putative structural or functional homologues of these genes, mraZ, mraW and mraR (now named yabB, yabC and $f t s L$, respectively), are present in the same location in the Escherichia coli chromosome and are believed to play similar roles in division (Ayala et al., 1994; Daniel et al., 1996).

Currently, the sequence and the organization of the $d c w$ clusters of Haemophilus influenzae (Fleischmann et al., 
1995; Lutkenhaus \& Addinall, 1997), Staphylococcus aureus (Pucci et al., 1997), Enterococcus faecalis (Pucci et al., 1997) and Enterococcus hirae (Duez et al., 1997) are available. While the Haemophilus influenzae dcw cluster is essentially identical to that of Escherichia coli, some differences were found in the comparison of this region to that of Gram-positive bacteria. Some genes encoding enzymes involved in the cytoplasmic step of peptidoglycan biosynthesis are not included in the cluster of Gram-positive bacteria (Buchanan et al., 1994; Pucci et al., 1997; Duez et al., 1997). In particular, the Bacillus subtilis cluster does not contain the equivalent of murF, murC and ddl (Buchanan et al., 1994). Consistently, these genes are missing, together with murE, in Enterococcus faecalis, Enterococcus hirae and Staphylococcus aureus, which also lacks murG (Pucci et al., 1997; Duez et al., 1997). However, since these genes are believed to be essential, they are expected to be placed in chromosomal locations other than the $d c w$ cluster. Interestingly, $f t s W$, which encodes an essential protein required at the early and late stages of division (Ishino et al., 1989; Khattar et al., 1994, 1997), is also missing from the $d c w$ cluster of all the Gram-positive bacteria analysed so far. However, a sporulation-specific locus, the $f t s W$ homologue spoVE, has been found between murD and murG in Bacillus subtilis (Ikeda et al., 1989; Henriques et al., 1992; Daniel \& Errington, 1993). Moreover, a gene encoding an FtsW-like protein has been found in Staphylococcus aureus (Pucci et al., 1997) and in Enterococcus hirae (O. Massidda, C. Duez, J. Coyette, G. D. Shockman \& L. Daneo-Moore, unpublished results; GenBank accession no. U58049) and in all cases mapped elsewhere in the chromosome.

The presence of the $d c w$ cluster in several different bacterial species has been interpreted to have regulatory and evolutionary implications (Vicente \& Errington, 1996; Hara et al., 1997; Watanabe et al., 1997). In this work we report the sequence and organization of the $d c w$ cluster of Streptococcus pneumoniae. We found that the organization of the $d c w$ genes differs in many respects from that of the clusters of other Gram-positive and Gram-negative bacteria reported so far. We also report the nucleotide sequence of a $3 \cdot 1 \mathrm{~kb}$ chromosomal region identified downstream of $f t s Z$. This region contains four ORFs encoding proteins of unknown function, followed by an ORF encoding the Bacillus subtilis DivIVA homologue, recently found to play a role in division (Cha \& Stewart, 1997; Edwards \& Errington, 1997). An ftsZ-divlVA intergenic region could also be amplified from the Staphylococcus aureus chromosome. Sequence analysis demonstrated that the similarity of the translated ORFs, as well as the genetic organization of this region, are also conserved in Streptococcus pyogenes and Bacillus subtilis. This raises the possibility that these previously unidentified genes may be important for division in Gram-positive bacteria.

\section{METHODS}

Bacterial strains. Streptococcus pneumoniae G54 is a recent clinical isolate of 19F capsular type (Pozzi et al., 1996). Fifteen additional Streptococcus pneumoniae clinical isolates were chosen from our laboratory strain collection to study the organization of the dcw cluster among different Streptococcus pneumoniae strains. Streptococcus pneumoniae strain $\mathrm{Rx} 1$ (Ravin, 1959) was also included in the study as an example of a well-characterized laboratory strain. Staphylococcus aureus ATCC 14154 was used for PCR amplification of the ftsZ-divIVA region.

DNA manipulation and sequence determination. Streptococcus pneumoniae genomic DNA was isolated from the clinical isolate $\mathrm{G} 54$ and purified with $\mathrm{CsCl}$ as described by Dillard \& Yother (1994). The DNA was mechanically sheared, end-repaired and ligated to M13mp18 (New England Biolabs), by using Bst XI cloning technology, to eliminate the background due to vector self-ligation and to avoid multiple inserts (Ausubel et al., 1991). Two libraries, having a mean insert size of 0.8 and $1.2 \mathrm{~kb}$, respectively, were constructed. Over 45000 independent clones were sequenced using a PRISM 377 DNA Sequencer (Applied Biosystems). Samples for sequencing were prepared with the PRISM dRhodamine Terminator Cycle Sequencing Ready Reaction Kit (Applied Biosystems) and sequences were assembled using a custom-designed program (M. De Francesco \& G. Feger, unpublished results).

PCR. A series of specific primers (synthesized at Genset Oligos, Paris, France) were designed on the basis of strain G54 sequence information and used for PCR experiments. PCR products were amplified from Streptococcus pneumoniae chromosomal DNA with 1 U Taq polymerase (Perkin-Elmer) in a $50 \mu \mathrm{l}$ reaction mixture in a Hybaid Thermocycler. The following temperature profile was used: $94^{\circ} \mathrm{C}$ for $60 \mathrm{~s}$ to denature, $53-60^{\circ} \mathrm{C}$ for $90 \mathrm{~s}$ to anneal primers and $72{ }^{\circ} \mathrm{C}$ for 120-150 s for extension. When the size of the expected products was larger than $3.0 \mathrm{~kb}$, the Expand Long Template PCR System (Boehringer Mannheim) was used, according to the manufacturer's instructions. The forward primers spFmurG (5' GCGATTTGACCTTGGATAGTTTGG $\left.3^{\prime}\right)$ and spFdivIB ( $5^{\prime}$ AGGTCAAGGAATATGATATTGTGG $3^{\prime}$ ) with the reverse primer spRpyrF ( $5^{\prime}$ TGGACGAATCCCTGGTGTCAG $\left.3^{\prime}\right)$, and the forward primers spFp $b p 2 b\left(5^{\prime}\right.$ ACCTTACAAATGGTGTCGGACCT $3^{\prime}$ ) and spFmurF (5' GCAAGAAGGAGTTTCAGAGGAGC $3^{\prime}$ ) with the reverse primers spR murF (5' GACGAGCCAATTCAGACAAGAGA $\left.3^{\prime}\right)$ and $\operatorname{spR} f t s A$ ( $5^{\prime}$ ATGACTTCACGGTCAGGTGTCAT $3^{\prime}$ ) were used to confirm the organization of the $d c w$ cluster (dcw2 and $d c w 1$, respectively) in different Streptococcus pneumoniae strains. The forward primer saFfts $Z$ ( $5^{\prime}$ CACTGGATTCGGAACAAGCGT $\left.3^{\prime}\right)$ and the reverse primer saRdivIVA (5' TCAATTTCAGTGCTTAGTTGCTCCA $\left.3^{\prime}\right)$, based on the sequences with GenBank accession nos U94706 and $\mathrm{U} 41072$, respectively, were used to amplify the ftsZ-divIVA region from Staphylococcus aureus chromosomal DNA. When necessary PCR-derived fragments were purified using the QIAquick PCR Purification Kit (Qiagen) and sequenced as described above.

Sequence analysis. Streptococcus pneumoniae $d c w$ genes were identified by sequence homology searches against the nonredundant database at NCBI, using BLASTP, BLASTP2 and BLASTX programs (Altschul et al., 1990, 1997; Gish \& States, 1993). In parallel, homology searches were done against specialized databases: Streptococcus pyogenes Genome BLAST Server (Roe et al., 1998) and the SubtiList Web Server at Pasteur Institute (Kunst et al., 1997). When necessary, raw nucleotide sequences were downloaded from the database and translated into ORFs using CLONE4 (Educational Software, Harrisburg, PA). Sequence similarities of the deduced gene 
products were searched for as described above. Additional computer analysis was performed using the Genetics Computer Group (GCG) package (Devereux et al., 1984).

\section{RESULTS AND DISCUSSION}

\section{Cloning, sequencing and characterization of the dcw gene cluster of Streptococcus pneumoniae}

The $d c w$ cluster was cloned as part of a whole-genome sequencing project. Two libraries, having mean insert sizes of 0.8 and $1.2 \mathrm{~kb}$, respectively, were constructed and over 45000 independent clones were sequenced. The correct contig assembly of the $d c w$ sequences was verified by PCR. On the basis of strain G54 sequence information, different sets of specific primers were designed and used to amplify the corresponding predicted fragments (varying from 1.5 to $2.0 \mathrm{~kb}$ ) from G54 chromosomal DNA. In all cases the amplified fragments matched the expected sizes (data not shown).

Three different contigs, containing the equivalent of most of the $d c w$ genes, corresponding to the $2 \mathrm{~min}$ region of the Escherichia coli chromosome were identified. The genetic organization and some features of the identified genes are shown in Table 1. A comparison of Streptococcus pneumoniae dcw clusters with the clusters of other bacteria reported to date is shown in Fig. 1. The first region of $10 \mathrm{~kb}$ (dcw1 cluster) contained five $d c w$ genes. The $f t s A$ and $f t s Z$ cell division genes were found at one end of this cluster, while at the other end $p b p 2 b$ (Dowson et al., 1989a) was found. Anomalously, the equivalent homologues of the genes usually found in the region downstream of $p b p B$ in other Gram-positive bacteria were missing from the cluster. Instead, this region contained $d d l$ and $m u r F$, so far found only in the $d c w$ cluster of Gram-negative species (see Fig. 1). Moreover, additional genes not explicitly related to cell division were found in the $d c w 1$ region. These genes included a recM homologue, located downstream of $p b p 2 b$, and a Bacillus subtilis mut T homologue followed by an ORF specific to Streptococcus pneumoniae, located downstream of murF. It is worth noting that a gene encoding the Streptococcus pneumoniae PBP2b homologue followed by recM has been recently identified in the closely related Streptococcus thermophilus (Stingele \& Mollet, 1996). murD, murG and $\operatorname{divIB}$, always found located upstream of $f t s A$, were found in a second region of $8 \mathrm{~kb}$, separate from the first, and named dcw2. In Streptococcus pneumoniae G54 the region downstream of $\operatorname{divIB}$ contained $p y r F$ and $p y r E$, encoding homologues of enzymes involved in the sixth and fifth step of pyrimidine biosynthesis, respectively, instead of $f t s A$. A third separate region of $6 \mathrm{~kb}$, named $d c w 3$, containing $y l l C$ and $y l l D$ but not $y l l B, p b p 2 x$

Table 1. Genetic organization and characteristics of the Streptococcus pneumoniae $d c w$ gene cluster

\begin{tabular}{|c|c|c|c|c|c|}
\hline \multirow{2}{*}{$\begin{array}{l}\text { Gene } \\
d c w l\end{array}$} & \multirow[t]{2}{*}{ End-points $(b p)^{*}$} & \multirow[t]{2}{*}{ Protein size (aa) } & \multicolumn{3}{|c|}{ Putative ribosome-binding site and translation start $\dagger$} \\
\hline & & & & & \\
\hline$p b p 2 b$ & $75>2117$ & 685 & AGAAAtGAGa & ctgatttgt & ATG aga aaa \\
\hline recM & $2128>2724$ & 198 & AttAgaaAGG & aacat & ATG ctt tat \\
\hline$d d l$ & $2900>3943$ & 347 & tagAAt tAGG & acAaataat & ATG aad caa \\
\hline murF & $4027>5400$ & 457 & ttAAAGGAGt & aGAa & ATG aaa tta \\
\hline$m u t T$ & $5387>5998$ & 203 & -------- & ---- & ATG a a cca \\
\hline orf1 & $6089>6793$ & 234 & AattAtGAGG & aagaCtag & ATG aat tta \\
\hline$f t s A$ & $7012>8385$ & 457 & gatAgaGAGG & aagcgatgtaa & ATG gct aga \\
\hline$f t s Z$ & $8402>9661$ & 419 & AatAAaGAGG & aaAataatt & ATG aca tet \\
\hline \multicolumn{6}{|l|}{$d c w 2$} \\
\hline murD & $2682>4034$ & 450 & gaAAtGGAGt & Tcgagac & ATG aa gta \\
\hline murG & $4038>5096$ & 352 & gtAgCGGAGt & TaAaagaataa & ATG aaa aaa \\
\hline $\operatorname{divIB}$ & $5106>6305$ & 399 & CatAAGGAaa & gtaa & ATG tca aa \\
\hline pyrF & $6538>7239$ & 233 & taAAAGGAGa & aacct & ATG cga gaa \\
\hline pyrE & $7273>7905$ & 210 & taAAAGGAGa & $\operatorname{atACC}$ & ATG aca ctt \\
\hline \multicolumn{6}{|l|}{$d c w 3$} \\
\hline yllC & $1134>2084$ & 316 & gGAtttGtGG & TaAaatagataagat & ATG aca aaa \\
\hline$y l l D$ & $2096>2413$ & 105 & AagtAaGAGG & gaAaag & ATG gca gaa \\
\hline \multirow[t]{2}{*}{$p b p 2 x$} & $2417>4669$ & 750 & AgAAtaGcGG & aGtaagat & ATG a ag tgg \\
\hline & & & or AtAgcGGAGt & aagat & \\
\hline$m r a Y$ & $4671>5651$ & 326 & ctttAGGAGa & ctaat & ATG tet att \\
\hline $16 \mathrm{~S}$ rRNA & & & $3^{\prime} \mathrm{OH}$-UCUUUCCUCC & ACUAG & \\
\hline
\end{tabular}

$*$ indicates the direction of transcription.

† Bases shown in bold upper case letters represent bases complementary to $16 S$ rRNA. Dashed lines indicate that no putative ribosomebinding site was found upstream of the identified translational start. Upper case letters in plain type indicate the putative translational start codon. 
Ec

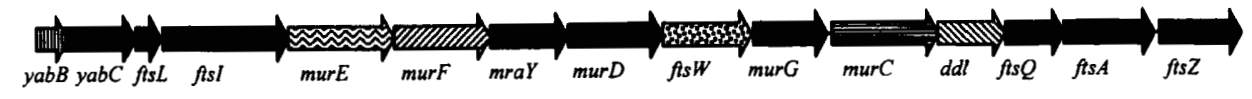

Bs

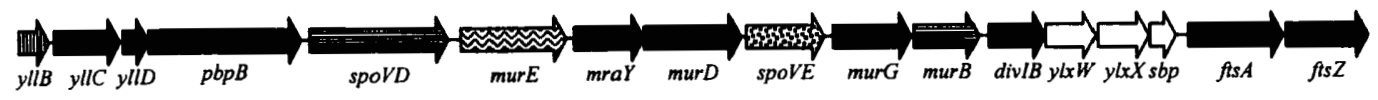

$\mathrm{Sa}$

Ef

Eh

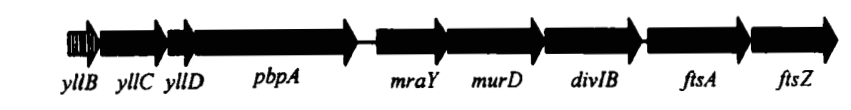

\title{
E
}

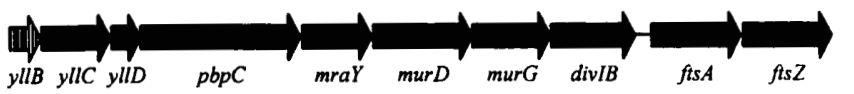

Spy
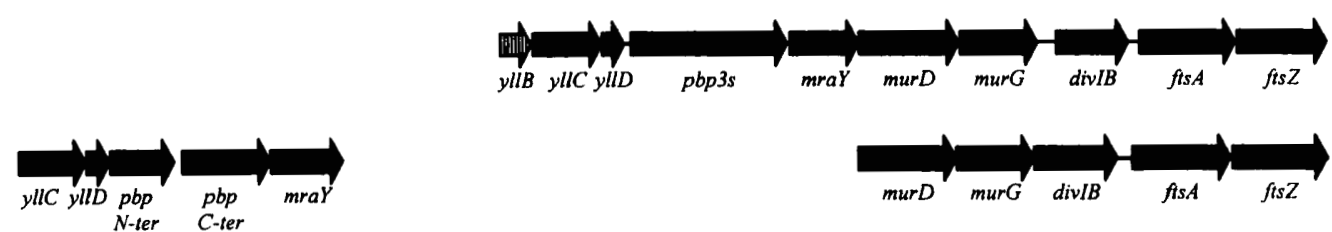

Spn
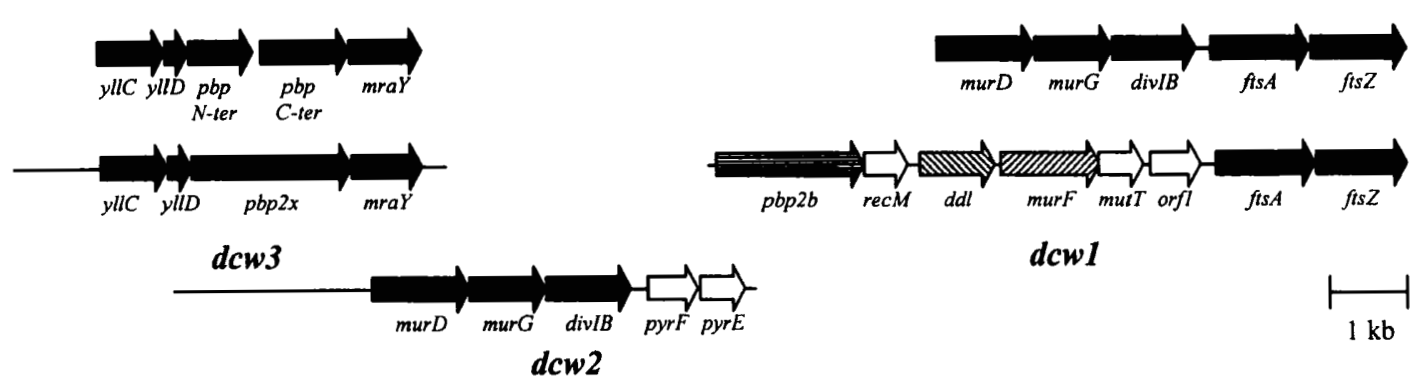

$d c w 1$

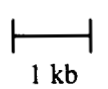

\begin{abstract}
Fig. 1. Comparison of the dcw gene clusters of Escherichia coli (Ec), Bacillus subtilis (Bs), Staphylococcus aureus (Sa), Enterococcus faecalis (Ef), Enterococcus hirae (Eh), Streptococcus pyogenes (Spy) and Streptococcus pneumoniae (Spn). The coding regions and their direction of transcription are indicated by arrows. Gene names are given under the corresponding coding region. dcw genes common to all the species, with the exception of murG which is absent in Staphylococcus aureus, are shown in black. dow genes found in at least two species are shown with a different pattern. Identical patterns in different species represent structural or functional homologues. dcw genes found only in one species are shown with horizontal hatching. ORFs that are not related to dcw genes are in white. For the purpose of comparison, coding regions constituting the $d c w 1,2$ and 3 clusters are aligned with the corresponding regions in the other species, as the organization of the chromosome is not yet known.
\end{abstract}

(Laible et al., 1989) and mraY homologues, was also identified. This sequence matched, in part, with a Streptococcus pneumoniae sequence in the database (GenBank accession no. Z79691).

Table 2 provides a quantitative description of the relationship between Streptococcus pneumoniae $d c w$ predicted proteins and their respective homologues for the bacteria included in Fig. 1. Streptococcus pyogenes was excluded from this comparison since the sequence data available are still preliminary (Roe et al., 1998) and translation of the ORFs has not always resulted in full length proteins. As expected, most of the Streptococcus pneumoniae dcw gene products, with the exception of YllD/FtsL and DivIB/FtsQ, showed high sequence similarity to their respective homologues, in particular to those of the more closely related enterococci. The highest degree of similarity was scored with the widespread tubulin-like FtsZ, the major component of the septal ring structure (for a comprehensive review see Lutkenhaus \& Addinall, 1997). Interestingly, the amino acid sequence corresponding to the GTP-binding motif of Streptococcus pneumoniae FtsZ differed from that of all other available Fts $Z$ sequences. This difference is due to a serine residue replacing a threonine in one of the completely conserved positions of the motif (not shown). This substitution may be common to streptococci, since it was also observed in the corresponding GTP-binding motif of the predicted Streptococcus pyogenes FtsZ. Studies of the biochemical activities of these proteins (i.e. GTP binding, GTPase activity and polymerization) may help in understanding the biological implication of the observed difference.

Two PBPs, PBP2x and PBP2b (penicillin-sensitive transpeptidases), belonging to the multimodular class B PBPs (Ghuysen, 1991), were found in the $d c w$ clusters of Streptococcus pneumoniae. Both PBPs account for resistance to $\beta$-lactam antibiotics in Streptococcus pneumoniae clinical isolates by showing decreased affinity for these drugs (Laible et al., 1991; Laible \& Hakenbeck, 1991; Dowson et al., 1989b). At the molecular level, resistance is achieved by replacing entire parts of the $p b p$ genes with the corresponding regions from closely related streptococcal species that have PBPs with lower affinities with respect to those of the pneumococcal homologues (Dowson et al., 1989b; Hakenbeck, 1998). One possible explanation for the presence of two PBPs associated with the $d c w$ genes is to assure the correct functioning of at least one PBP, since heterologous 
Table 2. Comparison of Streptococcus pneumoniae dcw gene products

\begin{tabular}{|c|c|c|c|c|c|}
\hline \multirow{2}{*}{$\begin{array}{l}\text { Streptococcus } \\
\text { pneumoniae } \\
\text { protein }\end{array}$} & \multicolumn{5}{|c|}{ Percentage identity ${ }^{*}$} \\
\hline & $\begin{array}{c}\text { Escherichia } \\
\text { coli }\end{array}$ & $\begin{array}{c}\text { Bacillus } \\
\text { subtilis }\end{array}$ & $\begin{array}{c}\text { Staphylococcus } \\
\text { aureus }\end{array}$ & $\begin{array}{c}\text { Enterococcus } \\
\text { faecalis }\end{array}$ & $\begin{array}{c}\text { Enterococcus } \\
\text { hirae }\end{array}$ \\
\hline PBP2b† & $20 \cdot 7(569)$ & $32.6(688)$ & ND & ND & ND \\
\hline DdlA & $34 \cdot 3(251)$ & $43 \cdot 1(348) \ddagger$ & ND & ND & ND \\
\hline MurF & $29 \cdot 8(382)$ & $38.0(458) \ddagger$ & ND & ND & ND \\
\hline FtsA & $33.0(358)$ & $40 \cdot 7(371)$ & $28 \cdot 1(462)$ & $53 \cdot 2(370)$ & $57 \cdot 4(394)$ \\
\hline FtsZ & $54.7(316)$ & $58.0(374)$ & $52.6(388)$ & $60 \cdot 0(420)$ & $62 \cdot 9(428)$ \\
\hline MurD & $31 \cdot 3(450)$ & $49 \cdot 4(449)$ & $46 \cdot 3(438)$ & $59.6(453)$ & $58.5(451)$ \\
\hline MurG & $27 \cdot 7(321)$ & $25.0(348)$ & ND & $26 \cdot 4(364)$ & $24 \cdot 2(359)$ \\
\hline DivIB $\$$ & $17 \cdot 1(246)$ & $25 \cdot 3(265)$ & $20 \cdot 4(402)$ & $22 \cdot 7(343)$ & $24 \cdot 4(271)$ \\
\hline YllC\| & $40 \cdot 1(319)$ & $61.6(310)$ & $59 \cdot 4(315)$ & $66 \cdot 3(315)$ & $67 \cdot 4(316)$ \\
\hline YllDg & - & $22.5 \quad(80)$ & $16 \cdot 3 \quad(86)$ & $30 \cdot 0(100)$ & $29 \cdot 6 \quad(54)$ \\
\hline PBP $2 x * *$ & $24 \cdot 1(323)$ & $33.6(351)$ & $29 \cdot 8(429)$ & $37 \cdot 5(750)$ & $41 \cdot 5(662)$ \\
\hline MraY & $47 \cdot 2(195)$ & $43 \cdot 1(318)$ & $42 \cdot 9(310)$ & $52.6(327)$ & $54 \cdot 8(310)$ \\
\hline
\end{tabular}

"Percentage identical amino acids determined by Lipman-Pearson protein alignment. Numbers in parentheses indicate the length of the amino acid overlap, including gaps. -, No significant similarity found; ND, not determined.

†PBP2 in Escherichia coli, PBP2A in Bacillus subtilis. The genes encoding these proteins are not located in the $d c w$ cluster.

$\ddagger$ The genes encoding DdlA and MurF in Bacillus subtilis are not located in the dcw cluster.

SFtsQ in Escherichia coli.

$\|$ YabC in Escherichia coli.

I FtsL in Escherichia coli.

*PBP3 in Escherichia coli, PBP2B in Bacillus subtilis, PBP1 in Staphylococcus aureus, PBP3 in Enterococcus faecalis, PBP3s in Enterococcus hirae.

recombinations often occur within the genes encoding these proteins (Dowson et al., 1989b; Hakenbeck, 1998). However, the previously reported findings that both PBP2x and PBP2b are essential (Kell et al., 1993) do not support this hypothesis. Alternatively, it is possible that one PBP is needed for cell wall elongation (PBP2b) and the other for septum formation (PBP2x). This is supported by the fact that PBP2x shows a higher degree of similarity to PBPs associated with septum formation (i.e. Escherichia coli PBP3 and homologous PBPs from other bacteria, always located in the $d c w$ cluster, see Table 2), while PBP2b shows higher similarity to PBPs involved in lateral elongation (i.e. Escherichia coli PBP2 and Bacillus subtilis PBP2A), which has been shown to occur in some Gram-positive cocci (Lleo et al., 1990).

\section{Analysis of the dcw cluster in different Streptococcus pneumoniae clinical isolates}

Contig assembly data obtained so far for Streptococcus pneumoniae G54 indicates that the $d c w$ clusters are physically separated in the chromosome by at least $40 \mathrm{~kb}$ each side. This is also supported by experiments with long-range PCR, to connect each cluster, which always resulted in absence of products (data not shown). According to the physical map for Streptococcus pneumoniae $\mathrm{R} 6$, a distance of at least $385 \mathrm{~kb}$ should separate $p b p 2 x$ and $p b p 2 b$ (Gasc et al., 1991).
Recently reported preliminary results indicated that Streptococcus pneumoniae has a $d c w$ cluster similar to that of other Gram-positive bacteria, in particular Streptococcus pyogenes (Pucci et al., 1997). Both streptococci showed the presence of $f t s A$ and $f t s Z$ at the distal end of the cluster and a PBP-encoding gene, $p b p 2 x$ in Streptococcus pneumoniae, followed by mraY at the proximal end (Pucci et al., 1997). These findings are different from the results obtained for Streptococcus pneumoniae G54 shown in Fig. 1.

To test the possibility that the observed differences reflected strain variability due to genomic rearrangements, the organization of the $d c w$ cluster was analysed in 15 additional independent Streptococcus pneumoniae strains, including Rx1. Different sets of primers were designed to amplify the region between $m u r G-d i v I B$ and $p y r F, p b p 2 b$ and $m u r F$, and $m u r F$ and $f t s A$. The sizes of the expected products were calculated on the basis of strain G54 sequence information. The resulting PCR products of two different strains, Streptococcus pneumoniae G54 and Rx1, were sequenced (data not shown).

The forward primers $\mathrm{spF} m u r G$ and $\mathrm{spF}$ divIB with the reverse primer spR $p y r F$ were expected to give 2123 and 1315 bp fragments, respectively. Of the 15 strains tested, 13 were identical to G54 and products of the expected size were amplified from all of them. In contrast, no amplicons were detected in strain $\mathrm{Rx} 1$ and in one other 


\section{$M \quad 1 \quad 2 \quad 3 \quad 4 \quad 5 \quad 6 \quad 7 \quad 8 \quad 9101112131415161718192021$}

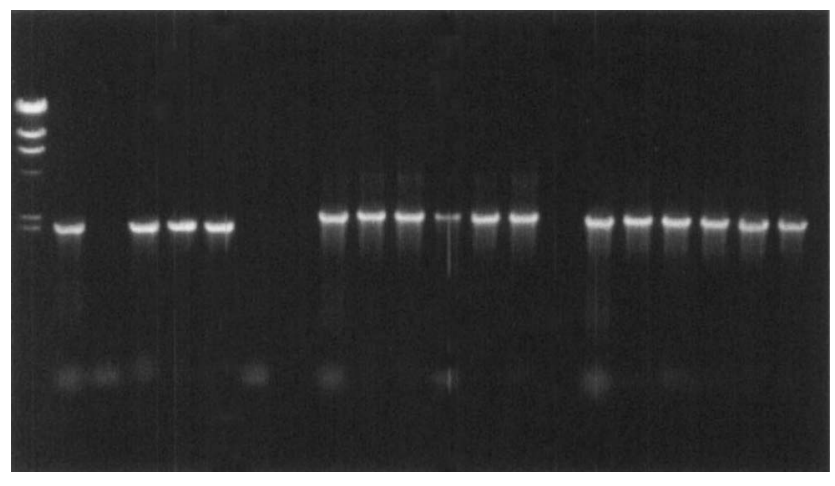

Fig. 2. $P C R$ analysis of $d c w$ clusters in different Streptococcus pneumoniae strains. Lanes: 1-6, PCR products from strains G54, Rx1，sp186, sp723，sp4636, sp4657 and sp3157, respectively, amplified with primers spFmurG and spRpyrF; 7, negative control (no DNA); 8-13, products from strains G54, Rx1, sp186, sp723, sp4636, sp4657 and sp3157, respectively, amplified with primers spFpbp2b and spRmurF; 14 , negative control (no DNA); 15-20 are products from strains G54, Rx1, sp186, sp723, sp4636, sp4657 and sp3157, respectively, amplified with primers spFmurF and spRftsA; 21, negative control (no DNA); $M$, HindlII-digested $\lambda$ phage DNA.

Streptococcus pneumoniae clinical isolate, even when parameters for long-range PCR were used. These results indicate that $p y r F-p y r E$ may not always be located downstream of divIB and suggest that chromosomal rearrangements may have occurred outside the $d c w 2$ cluster in different Streptococcus pneumoniae strains. The forward primers spFpbp $2 b$ and $\mathrm{spF} m u r F$ with the reverse primers $\mathrm{spR}$ murF and $\mathrm{spR} f t s A$ were expected to give 2512 and 2505 bp fragments, respectively. All the 15 strains tested gave fragments of the expected size, consistent with the results obtained for Streptococcus pneumoniae G54. The results for six of these strains are shown in Fig. 2.

Taken together these results indicate that, although some variations were observed among different Streptococcus pneumoniae isolates, the genetic organization of the $d c w$ clusters of G54 is representative of Streptococcus pneumoniae. This organization substantially differs from that of other eubacterial species for which the $d c w$ cluster has been characterized.

\section{Identification and characterization of the chromosomal region downstream of $\mathrm{fts} Z$ in Streptococcus pneumoniae and Staphylococcus aureus}

Analysis of the region downstream of $f t s Z$ in Streptococcus pneumoniae revealed the presence of five ORFs transcribed in the same direction as the $d c w$ genes and tightly packed together (Table 3 ). The deduced amino acid sequences of the first four ORFs showed a high level

Table 3. Genetic organization and characteristics of the chromosomal region downstream of ftsZ in Streptococcus pneumoniae and Staphylococcus aureus

\begin{tabular}{|c|c|c|c|c|c|c|}
\hline Gene & End-points $(\mathbf{b p})^{*}$ & \multicolumn{3}{|c|}{ Putative ribosome-binding site and translation start $†$} & Similarity index $\neq$ & $P$ value $\$$ \\
\hline \multicolumn{7}{|c|}{ Streptococcus pneumoniae } \\
\hline$y \operatorname{lm} E$ & $9666>10337$ & -------- & ---- & ATG a at gta & $42(\mathrm{I}), 63(\mathrm{~S})(220)$ & $1.3 \times 10^{-46}$ \\
\hline$y \operatorname{lm} F$ & $10347>10886$ & $\begin{array}{r}t t t \text { AAGtAGG } \\
\text { or AagtagGaGa }\end{array}$ & $\begin{array}{l}\text { aGAgaacc } \\
\text { gaACC }\end{array}$ & ATG tct tta & 27 (I), 52 (S) (159) & $4.0 \times 10^{-13}$ \\
\hline$y \operatorname{lm} G$ & $10886>11149$ & gaaAtaGAGt & acgata & ATG att tet & $36(\mathrm{I}), 60(\mathrm{~S}) \quad(75)$ & $1.4 \times 10^{-10}$ \\
\hline$y \operatorname{lm} H$ & $11146>11931$ & tttct $\mathbf{G G C G a}$ & TGATagg & ATG aat aaa & 32 (I), 58 (S) (252) & $3.5 \times 10^{-39}$ \\
\hline $\operatorname{divIVA}$ & $11940>12728$ & gtAAg tGAGG & aataga & ATG cca att & $36(\mathrm{I}), 66(\mathrm{~S})(163)$ & $1.4 \times 10^{-28}$ \\
\hline $16 \mathrm{~S}$ rRNA & & OH-UCUUUCCUCC & ACUAG & & & \\
\hline \multicolumn{7}{|c|}{ Staphylococcus aureus } \\
\hline$y \operatorname{lm} D$ & $437>1228$ & AtgAtGGtGa & cGATCga & GTG aat gat & $31(\mathrm{I}), 55(\mathrm{~S})(247)$ & $1.3 \times 10^{-39}$ \\
\hline$y \operatorname{lm} E$ & $1246>1920$ & AaCAAGGAGG & aGATatgt & TTG cgt gtg & 55 (I), 72 (S) (224) & $9 \cdot 3 \times 10^{-62}$ \\
\hline$y \operatorname{lm} F$ & $1926>2480$ & gGAgAaGAGG & aGtgagccac & TTG get tta & 52 (I), 67 (S) (129) & $1 \cdot 2 \times 10^{-31}$ \\
\hline$y \operatorname{lm} G$ & $2492>2782$ & AC tAAGGAGt & TaAcat & ATG gat ata & 51 (I), 67 (S) (87) & $1.7 \times 10^{-21}$ \\
\hline$y \operatorname{lm} H$ & $2865>3671$ & tatAAGGgCa & atAg & ATG gta ttt & $40(\mathrm{I}), 62$ (S) (251) & $7 \cdot 1 \times 10^{-48}$ \\
\hline divIVA & $3695>4312$ & tttAAGGAGG & aTAaCaa & ATG cct tet & 41 (I), 72 (S) (158) & $8.5 \times 10^{-36}$ \\
\hline $16 \mathrm{~S}$ rRNA & & $\mathrm{OH}$-UCUUUCCUCC & ACUAG & & & \\
\hline
\end{tabular}

* $>$ indicates the direction of transcription.

† Bases shown in bold upper case letters represent bases complementary to $16 \mathrm{~S}$ rRNA. Dashed lines indicate that no putative ribosomebinding site was found upstream of the identified translational starts. Upper case letters in plain type indicate the putative translational start codon.

$\ddagger$ Percentage identity $(\mathbf{I})$ and percentage similarity $(\mathrm{S})$ as determined with the BLAST 2 program. Numbers in parentheses indicate the length of the amino acid overlap, including gaps.

$\mathbb{S T h e} P$ value indicates the statistical significance of the alignments. The lower the $P$ value, the greater the significance. 


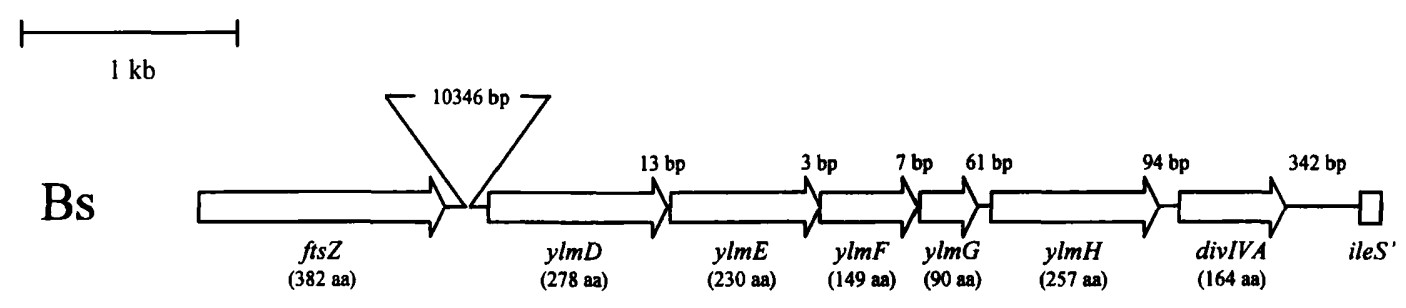

$\mathrm{Sa}$

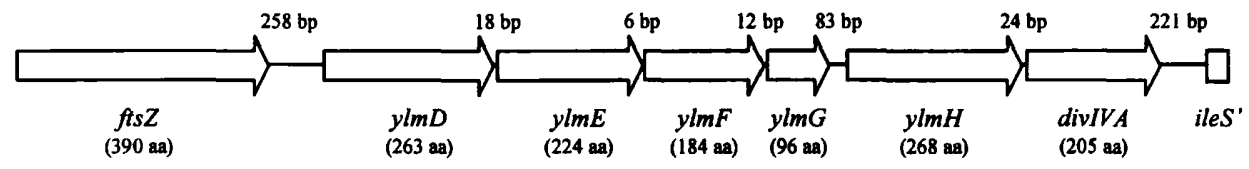

Spn

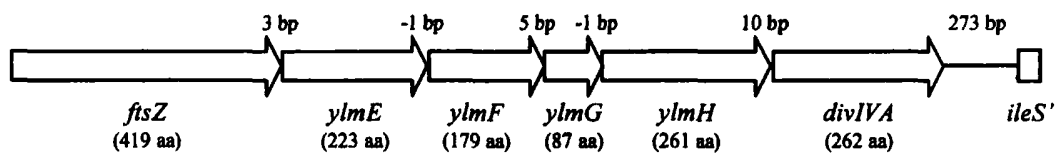

Spy

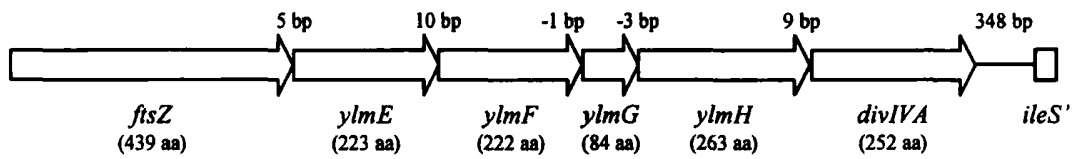

Fig. 3. Comparison of the region downstream of ftsZ in Bacillus subtilis (Bs), Staphylococcus aureus (Sa), Streptococcus pneumoniae (Spn) and Streptococcus pyogenes (Spy). The coding regions and their direction of transcription are indicated by arrows. Gene names are given under the corresponding coding region. Numbers in parentheses indicate the size of the translated gene products. The gaps between adjacent coding regions are indicated. Note that ileS is always located downstream of divIVA.

of sequence similarity with the $y \operatorname{lmE}, y \operatorname{lm} F, y \operatorname{lm} G$ and $y / m H$ gene products of Bacillus subtilis whose functions are unknown. The last ORF showed a high level of sequence similarity $(36 \%$ identity, $65 \%$ similarity over $163 \mathrm{aa}$ ) to the $\operatorname{divIVA}$ gene product of Bacillus subtilis, recently found to be involved in division (Cha \& Stewart, 1997; Edwards \& Errington, 1997), and 31\% identity and $56 \%$ similarity over 166 aa to a $23.5 \mathrm{kDa}$ protein encoded by an ORF of unknown function located upstream of ileS of Staphylococcus aureus (Chalker et al., 1994; Grundy et al., 1997). DivIVA also shared sequence similarity with antigen 84 (Hermans $e t$ al., 1995; Philipp et al., 1996), a cytoplasmic protein of unknown function of Mycobacterium tuberculosis and Mycobacterium leprae ( $22 \%$ identity, $40 \%$ similarity over 206 aa and $20 \%$ identity, $40 \%$ similarity over $255 \mathrm{aa}$, respectively) and the Bacillus subtilis $y$ psB product $(38 \%$ identity, $64 \%$ similarity over $57 \mathrm{aa}$ ). $y p s B$, which encodes a hypothetical protein of $98 \mathrm{aa}$, is located in a region of the Bacillus subtilis chromosome that contains the gene encoding PBP1A. Orthologues of this gene are found in a similar position in the Streptococcus pneumoniae and Streptococcus pyogenes genome (not shown).

From the analysis of the available sequence data we observed that the organization of the genes in the region downstream of $f t s Z$ is remarkably conserved in Bacillus subtilis and Streptococcus pyogenes. To test the possibility that a similar region was also conserved in other Gram-positive bacteria, we designed a forward primer based on the Staphylococcus aureus fts $Z$ gene (Pucci et al., 1997) and a reverse primer based on the ORF encoding the Staphylococcus aureus DivIVA homologue (Chalker et al., 1994), taking advantage of the available sequences in the database. These primers were used in PCR experiments to amplify a putative $f t s Z-d i v I V A$ region and to confirm the hypothesis that this region was conserved in other Gram-positive species. Indeed, a $3.7 \mathrm{~kb}$ fragment was amplified from Staphylococcus aureus chromosomal DNA. The nucleotide sequence of the amplified DNA fragment was determined by primer walking and analysed with CLONE4. The genetic organization and some features of the proteins encoded by the genes located downstream of $f t s Z$ and their similarity to the respective Bacillus subtilis homologues are shown in Table 3. Fig. 3 shows the map of this region in Staphylococcus aureus, Streptococcus pneumoniae and Streptococcus pyogenes in comparison with that of Bacillus subtilis, as taken from the Bacillus subtilis genomic database. In Streptococcus pyogenes these ORFs are located immediately after $f t s Z$ and appear to be part of the same cluster, similar to Streptococcus pneumoniae. In Bacillus subtilis they also appear to be 
clustered together, but lie in a chromosomal region about $10 \mathrm{~kb}$ downstream of $f t s Z$ (Kunst et al., 1997). As shown in Fig. 3, in Stapbylococcus aureus and Bacillus subtilis an additional gene, $y \operatorname{lmD}$, was found upstream of $y / \mathrm{mE}$. The deduced amino acid sequences of the $y \operatorname{lmD}$ genes displayed similarity to a number of proteins of comparable size from other Gram-positive and Gramnegative bacteria. Consistent with the results shown in Fig. 3, all the YlmD homologues of other Gram-positive bacteria (Mycobacterium tuberculosis, Corynebacterium glutamicum, Streptomyces griseus), detected by searching the database, were located immediately downstream of $f t s Z$. However, $y \operatorname{lmD}$ was not found in streptococci, neither in the region $3^{\prime}$ to $f t s Z$ nor elsewhere in the available genome $194 \%$ of Streptococcus pneumoniae and $95 \%$ of Streptococcus pyogenes). The $y / m E$ gene product showed sequence similarity to a number of hypothetical proteins of comparable size belonging to the UPF0001 family, homologues to the Escherichia coli yggS gene product and present in both prokaryotes and eukaryotes (Saccharomyces cerevisiae and Caenorhabditis elegans). Proteins significantly similar to $y / m F$ products were found only in Mycobacterium tuberculosis (Philipp et al., 1996) and Synechocystis sp. (Kaneko et al., 1996a, b) while significant scores for the $y \operatorname{lmH}$ products were only detected in Synechocystis sp. (Kaneko et al., 1996a, b). Products of the $y \mathrm{lmG}$ genes of Streptococcus pneumoniae, Streptococcus pyogenes, Staphylococcus aureus and Bacillus subtilis all shared a good degree of mutual similarity. However, ambiguous results were obtained when individual proteins were tested against the database. In particular, while the streptococcal $y \operatorname{lm} G$ products gave a significant score only with a similar sized protein of Synechocystis sp., the $y \operatorname{lm} G$ products of Staphylococcus aureus and Bacillus subtilis shared similarity with proteins of the same or larger size encoded by genes belonging to the Escherichia coli yggT family present in several Gram-positive and Gramnegative species. Common to all $y \operatorname{lm} G$ products was a putative transmembrane domain, in agreement with the prediction that some of the possible distant homologues are integral membrane proteins.

\section{General features of the Streptococcus pneumoniae dcw cluster and conclusions}

The $d c w$ cluster is one of the best examples of highly conserved regions that survived the dynamic rearrangements often observed in eubacterial genomes during evolution (Watanabe et al., 1997). The biological reason for this conservation may be mainly attributed to the fact that this organization facilitates coordinated regulation of gene expression. A complex pattern of regulation within the $d c w$ genes has been well documented for Escherichia coli (Sullivan \& Donachie, 1984; Ayala et al., 1994; Palacios et al., 1996; Cam et al., 1996; Flardh et al., 1997; Hara et al., 1997). It remains to be verified if this can be extended to other eubacteria.

As observed by Pucci et al. (1997), in Gram-positive bacteria, unlike Escherichia coli, the constituent genes of the $d c w$ cluster, perhaps with the exception of $f t s A$ and $f t s Z$, are not necessarily tightly packed together and often show intergenic spacing of variable size. This is particularly evident in Streptococcus pneumoniae where some of the $d c w$ genes are located in physically distinct chromosomal regions. The significance of the unconventional organization observed for the Streptococcus pneumoniae cluster is not yet clear, but will possibly emerge from the analysis of the $d c w$ clusters of other closely related streptococcal species.

We have also reported the sequence of the chromosomal region downstream of $f t s Z$, consisting of genes transcribed in the same direction as the $d c w$ genes. This region appears to be very well conserved in a number of different Gram-positive species (Fig. 3). The last gene of the cluster encodes a protein sharing high sequence similarity with the divIVA gene product of Bacillus subtilis (Cha \& Stewart, 1997). Recently, DivIVA has been proposed to be the Bacillus subtilis counterpart of Escherichia coli MinE, whose structural homologue is missing in Bacillus subtilis and has been shown to act as a pilot protein in determining division-site selection (Cha \& Stewart, 1997; Edwards \& Errington, 1997). Preliminary results, obtained in our laboratory by disrupting the gene encoding the Streptococcus pneumoniae DivIVA homologue, are consistent with a similar role for this protein. Inactivation of $\operatorname{divIVA}$ in Streptococcus pneumoniae resulted in severe growth inhibition and formation of chains of unseparated cells, some of them devoid of nucleoids (O. Massidda, unpublished results). The functions of the genes between $f t s Z$ and $\operatorname{divIVA}$ remain to be evaluated. However, their organization and chromosomal position suggest a possible role in division. Gene inactivation experiments to study the function of the ORFs located downstream of fts $Z$ are currently in progress in Streptococcus pneumoniae.

Although the $d c w$ cluster has been characterized in many different bacteria, the identification of this cluster in Streptococcus pneumoniae provides additional information for the understanding of the evolutionary origin of these genes and their regulation. Moreover, it provides a basis to evaluate, at the molecular level, how division occurs in Gram-positive cocci. Among Grampositive cocci, streptococci represent a simplified model of division, since they divide only in one plane of space. Furthermore, the ease of genetic manipulation of Streptococcus pneumoniae offers a good complement to Bacillus subtilis.

\section{ACKNOWLEDGEMENTS}

The authors thank E. Domenici for constant advice and support, and M. B. Whalen for helpful discussions. We are grateful to F. Faggioni and M. Guerrini for technical assistance. We also thank J. Coyette and C. Duez for providing us with unpublished results. O. Massidda was sponsored by the Cell Factory Contract No. CT96-0122 from the European Commission (DGXII) Biotechnology Program. 


\section{REFERENCES}

Altschul, S. F., Gish, W., Miller, W., Myers, E. W. \& Lipman, D. J. (1990). Basic local alignment search tool. J Mol Biol 215, 403-410.

Altschul, S. F., Madden, T. L., Schaffer, A. A., Zhang, J., Zhang, Z., Miller, W. \& Lipman, D. J. (1997). Gapped BLAST and PSI-BLAST: a new generation of protein database search programs. Nucleic Acids Res 25, 3389-3402.

Ausubel, F. M., Brent, R., Kingston, R. E., Moore, D. D., Seidman, J. G. \& Struhl, K. (1991). Current Protocols in Molecular Biology. New York: Wiley.

Ayala, J. A., Garrido, T., de Pedro, M. A. \& Vicente, M. (1994). Molecular biology of bacterial septation. In Bacterial Cell Wall, pp. 73-102. Edited by J.-M. Ghuysen \& R. Hakenbeck. Amsterdam: Elsevier.

Buchanan, C. E., Henriques, A. O. \& Piggot, P. J. (1994). Cell wall changes during bacterial endospore formation. In Bacterial Cell Wall, pp. 167-186. Edited by J.-M. Ghuysen \& R. Hakenbeck. Amsterdam: Elsevier.

Cam, K., Rome, G., Krisch, H. M. \& Bouche, J. P. (1996). RNase E processing of essential cell division genes mRNA in Escherichia coli. Nucleic Acids Res 24, 3065-3070.

Cha, J. H. \& Stewart, G. C. (1997). The divlVA minicell locus of Bacillus subtilis. J Bacteriol 179, 1671-1683.

Chalker, A. F., Ward, J. M., Fosberry, A. P. \& Hodgson, J. E. (1994). Analysis and toxic overexpression in Escherichia coli of a staphylococcal gene encoding isoleucyl-tRNA synthetase. Gene 141, 103-108.

Daniel, R. A. \& Errington, J. (1993). DNA sequence of the murE-murD region of Bacillus subtilis 168. J Gen Microbiol 139, 361-370.

Daniel, R. A., Drake, S., Buchanan, C. E., Scholle, R. \& Errington, J. (1994). The Bacillus subtilis spoVD gene encodes a mother-cellspecific penicillin-binding protein required for spore morphogenesis. J Mol Biol 235, 209-220.

Daniel, R. A., Williams, A. M. \& Errington, J. (1996). A complex four-gene operon containing essential cell division gene $p b p B$ in Bacillus subtilis. J Bacteriol 178, 2343-2350.

Devereux, J., Haeberli, P. \& Smithies, O. (1984). A comprehensive set of sequence analysis programs for the VAX. Nucleic Acids Res 12, 387-395.

Dillard, J. P. \& Yother, J. (1994). Genetic and molecular characterization of capsular polysaccharide biosynthesis in Streptococcus pneumoniae type 3. Mol Microbiol 12, 959-972.

Dowson, C. G., Hutchison, A. \& Spratt, B. G. (1989a). Nucleotide sequence of the penicillin-binding protein $2 B$ gene of Streptococcus pneumoniae strain R6. Nucleic Acids Res 17, 7518.

Dowson, C. G., Hutchison, A., Brannigan, J. A., George, R. C., Hansman, D., Linares, J., Tomasz, A., Smith, J. M. \& Spratt, B. G. (1989b). Horizontal transfer of penicillin-binding protein genes in penicillin-resistant clinical isolates of Streptococcus pneumoniae. Proc Natl Acad Sci USA 86, 8842-8846.

Duez, C., Thamm, I., Sapunaric, F., Coyette, J. \& Ghuysen, J.-M. (1997). The division and cell wall gene cluster of Enterococcus birae S185. DNA Seq 7, 1-13.

Edwards, D. H. \& Errington, J. (1997). The Bacillus subtilis DivIVA protein targets to the division septum and controls the site specificity of cell division. Mol Microbiol 24, 905-915.

Flardh, K., Garrido, T. \& Vicente, M. (1997). Contribution of individual promoters in the $d d l B-f t s Z$ region to the transcription of the essential cell-division gene fts $Z$ in Escherichia coli. Mol Microbiol 24, 927-936.
Fleischmann, R. D., Adams, M. D., White, O. \& 37 other authors (1995). Whole-genome random sequencing and assembly of Haemophilus influenzae Rd. Science 269, 496-512.

Gasc, A.-M., Kauc, L., Barraille, P., Sicard, M. \& Goodgal, S. (1991). Gene localization, size and physical map of the chromosome of Streptococcus pneumoniae. J Bacteriol 173, 7361-7367.

Ghuysen, J. M. (1991). Serine beta-lactamases and penicillinbinding proteins. Annu Rev Microbiol 45, 37-67.

Gish, W. \& States, D. J. (1993). Identification of protein coding regions by database similarity search. Nature Genet 3, 266-272.

Grundy, F. J., Haldeman, M. T., Hornblow, G. M., Ward, J. M., Chalker, A. F. \& Henkin, T. M. (1997). The Staphylococcus aureus ileS gene, encoding isoleucyl-tRNA synthetase, is a member of the T-box family. J Bacteriol 179, 3767-3772.

Hakenbeck, R. (1998). Mosaic genes and their role in penicillinresistant Streptococcus pneumoniae. Electrophoresis 19, 597-601.

Hara, H., Yasuda, S., Horiuchi, K. \& Park, J. T. (1997). A promoter for the first nine genes of the Escherichia coli mra cluster of cell division and cell envelope biosynthesis genes, including $\mathrm{ftsl}$ and ftsW. J Bacteriol 179, 5802-5811.

Henriques, A. O., de Lencastre, H. \& Piggot, P. J. (1992). A Bacillus subtilis morphogene cluster that includes spoVE is homologous to the mra region of Escherichia coli. Biochimie 74, 735-748.

Hermans, P. W., Abebe, F., Kuteyi, V. I., Kolk, A. H., Thole, J. E. \& Harboe, M. (1995). Molecular and immunological characterization of the highly conserved antigen 84 from Mycobacterium tuberculosis and Mycobacterium leprae. Infect Immun 63, 954-960.

Ikeda, M., Sato, T., Wachi, M., Jung, H. K., Ishino, F., Kobayashi, Y. \& Matsuhashi, M. (1989). Structural similarity among Escherichia coli FtsW and RodA proteins and Bacillus subtilis SpoVE protein, which function in cell division, cell elongation and spore formation, respectively. J Bacteriol 171, 6375-6378.

Ishino, F., Jung, H. K., Ikeda, M., Doi, M., Wachi, M. \& Matsuhashi, M. (1989). New mutations $f t s-36, l t s-33$ and $f t s W$ clustered in the mra region of the Escherichia coli chromosome induce thermosensitive cell growth and division. J Bacteriol 171, 5523-5530.

Kaneko, T., Sato, S., Kotani, H. \& 21 other authors (1996a). Sequence analysis of the genome of the unicellular cyanobacterium Synechocystis sp. strain PCC6803. II. Sequence determination of the entire genome and assignment of potential protein-coding regions. DNA Res 3, 109-136.

Kaneko, T., Sato, S., Kotani, H. \& 21 other authors (1996b). Sequence analysis of the genome of the unicellular cyanobacterium Synechocystis sp. strain PCC6803. II. Sequence determination of the entire genome and assignment of potential protein-coding regions (supplement). DNA Res 3, 185-209.

Kell, C. M., Sharma, U. K., Dowson, C. G., Town, C., Balganesh, T. S. \& Spratt, B. G. (1993). Deletion analysis of the essentiality of penicillin-binding proteins $1 \mathrm{~A}, 2 \mathrm{~B}$ and $2 \mathrm{X}$ of Streptococcus pneumoniae. FEMS Microbiol Lett 106, 171-175.

Khattar, M. M., Begg, K. J. \& Donachie, W. D. (1994). Identification of Fts W and characterization of a new $\mathrm{fts}$ W division mutant of Escherichia coli. J Bacteriol 176, 7140-7147.

Khattar, M. M., Addinall, S. G., Stedul, K. H., Boyle, D. S., Lutkenhaus, J. \& Donachie, W. D. (1997). Two polypeptide products of the Escherichia coli cell division gene $f t \mathrm{~W}$ and a possible role for FtsW in FtsZ function. J Bacteriol 179, 784-793.

Kunst, F., Ogasawara, N., Moszer, I. \& 148 other authors (1997). The complete genome sequence of the Gram-positive bacterium Bacillus subtilis. Nature 390, 249-256. 
Laible, G. \& Hakenbeck, R. (1991). Five independent combinations of mutations can result in low-affinity penicillin-binding protein $2 \mathrm{x}$ of Streptococcus pneumoniae. J Bacteriol 173, 6986-6990.

Laible, G., Hakenbeck, R., Sicard, M. A., Joris, B. \& Ghuysen, J. M. (1989). Nucleotide sequences of the $p b p X$ genes encoding the penicillin-binding proteins $2 \mathrm{x}$ from Streptococcus pneumoniae R6 and a cefotaxime-resistant mutant, C506. Mol Microbiol 3, $1337-1348$.

Laible, G., Spratt, B. G. \& Hakenbeck, R. (1991). Interspecies recombinational events during the evolution of altered PBP $2 x$ genes in penicillin-resistant clinical isolates of Streptococcus pneumoniae. Mol Microbiol 5, 1993-2002.

Lleo, M. M., Canepari, P. \& Satta, G. (1990). Bacterial cell shape regulation: testing of additional predictions unique to the twocompeting-sites model for peptidoglycan assembly and isolation of conditional rod-shaped mutants from some wild-type cocci. J Bacteriol 172, 3758-3771.

Lutkenhaus, J. \& Addinall, S. G. (1997). Bacterial cell division and the $\mathrm{Z}$ ring. Annu Rev Biochem 66, 93-116.

Palacios, P., Vicente, M. \& Sanchez, M. (1996). Dependency of Escherichia coli cell-division size and independency of nucleoid segregation on the mode and level of $\mathrm{fts} Z$ expression. Mol Microbiol 20, 1093-1098.

Philipp, W. J., Poulet, S., Eigimeier, K., Pascopella, L., Balasubramanian, V., Heym, B., Bergh, S., Bloom, B. R., Jacobs, W. R., Jr $\&$ Cole, S. T. (1996). An integrated map of the genome of the tubercle bacillus, Mycobacterium tuberculosis H37Rv and comparison with Mycobacterium leprae. Proc Natl Acad Sci USA 93, 3132-3137.

Pozzi, G., Masala, L., lannelli, F., Manganelli, R., Havarstein, L., Piccoli, L., Simon, D. \& Morrison, D. A. (1996). Competence for genetic transformation in encapsulated strains of Streptococcus pneumoniae: two allelic variants of the peptide pheromone. J Bacteriol 178, 6087-6090.
Pucci, M. J., Thanassi, J. A., Discotto, L. F., Kessler, R. E. \& Dougherty, T. J. (1997). Identification and characterization of cell wall cell division gene clusters in pathogenic Gram-positive cocci. J Bacteriol 179, 5632-5635.

Ravin, A.W. (1959). Reciprocal capsular transformations of pneumococci. J Bacteriol 77, 296-309.

Roe, B. A., Linn, S. P., Song, L., Yuan, X., Clifton, S., McShan, M. \& Ferretti, J. (1998). Streptococcal Genome Sequencing Project (funded by USPHS/NIH grant AI38406). University of Oklahoma.

Stingele, F. \& Mollet, B. (1996). Disruption of the gene encoding penicillin-binding protein $2 \mathrm{~b}(p b p 2 b)$ causes altered cell morphology and cease in exopolysaccharide production in Streptococcus thermophilus Sfi6. Mol Microbiol 22, 357-366.

Sullivan, N. F. \& Donachie, W. D. (1984). Transcriptional organization within an Escherichia coli cell division gene cluster: direction of transcription of the cell separation gene envA. $J$ Bacteriol 160, 724-732.

Vicente, M. \& Errington, J. (1996). Structure, function and controls in microbial division. Mol Microbiol 20, 1-7.

Watanabe, H., Mori, H., Itoh, T. \& Gojobori, T. (1997). Genome plasticity as a paradigm of eubacteria evolution. J Mol Evol 44 Suppl. 1, S57-S64.

Yanouri, A., Daniel, R. A., Errington, J. \& Buchanan, C. E. (1993). Cloning and sequencing of the cell division gene $p b p B$, which encodes penicillin-binding protein $2 \mathrm{~B}$ in Bacillus subtilis. J Bacteriol 175, 7604-7616.

Yura, T., Mori, H., Nagai, H., Nagata, T., Ishihama, A., Fujita, N., Isono, K., Mizobuchi, K. \& Nakata, A. (1992). Systematic sequencing of the Escherichia coli genome: analysis of the 0-2.4 min region. Nucleic Acids Res 20, 3305-3308.

Received 4 June 1998; revised 14 July 1998; accepted 3 August 1998. 